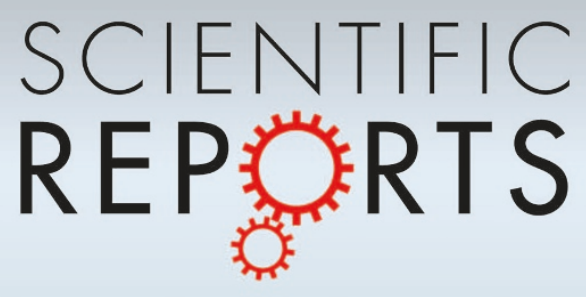

OPEN

SUBJECT AREAS:

NANOSCALE MATERIALS

ENVIRONMENTAL CHEMISTRY

Received

15 July 2013

Accepted

4 September 2013

Published

23 September 2013

Correspondence and requests for materials should be addressed to

Y.B. (yingpubi@licp. cas.cn)

\section{Visible-light-driven photoelectrochemical} and photocatalytic performances of Cr-doped $\mathrm{SrTiO}_{3} / \mathrm{TiO}_{2}$ heterostructured nanotube arrays

\author{
Zhengbo Jiao', Tao Chen', Jinyan Xiong', Teng Wang' ', Gongxuan Lu', Jinhua Ye' \& Yingpu Bi'
}

\begin{abstract}
'State Key Laboratory for Oxo Synthesis \& Selective Oxidation, and National Engineering Research Center for Fine Petrochemical Intermediates, Lanzhou Institute of Chemical Physics, CAS, Lanzhou 730000, China, ${ }^{2}$ International Center for Materials Nanoarchitectonics (MANA), and Research Unit for Environmental Remediation Materials, National Institute for Materials Science, Tsukuba, 305-0047, Japan.
\end{abstract}

Well-aligned $\mathrm{TiO}_{2}$ nanotube arrays have become of increasing significance because of their unique highly ordered array structure, high specific surface area, unidirectional charge transfer and transportation features. However, their poor visible light utilization as well as the high recombination rate of photoexcited electron-hole pairs greatly limited their practical applications. Herein, we demonstrate the fabrication of visible-light-responsive heterostructured $\mathrm{Cr}$-doped $\mathrm{SrTiO}_{3} / \mathrm{TiO}_{2}$ nanotube arrays by a simple hydrothermal method, which facilitate efficient charge separation and thus improve the photoelectrochemical as well as photocatalytic performances.

ne-dimensional $\mathrm{TiO}_{2}$ array architectures, especially well-aligned $\mathrm{TiO}_{2}$ nanotube arrays, exhibit promising photoelectric and photocatalytic performances in solar cells, water splitting and photocatalytic systems because of their unique highly ordered array structure, high specific surface area, unidirectional charge transfer and transportation features ${ }^{1-5}$. However, their poor visible light utilization as well as the high recombination rate of photoexcited electron-hole pairs greatly limit their practical applications ${ }^{6-8}$. Thereby, much effort has been devoted to the design and construction of novel hetero-composite structures to address these issues, such as metal or non-metal ion doping, noble metal loading, and hetero-coupling ${ }^{9-12}$. In terms of semiconductor heterojunctions, $\mathrm{SrTiO}_{3}$, whose conduction band edge is $200 \mathrm{mV}$ more negative than $\mathrm{TiO}_{2}$, have been considered as an alternate candidate for improving photoelectrochemical and photocatalytic performances by shifting the Fermi level of $\mathrm{TiO}_{2}$ nanostructure to more negative potentials ${ }^{13-17}$. Additionally, the coupling of $\mathrm{SrTiO}_{3}$ and $\mathrm{TiO}_{2}$ into a proper hetero-architecture can effectively facilitate the separation of photogenerated electrons and holes between $\mathrm{SrTiO}_{3}$ and $\mathrm{TiO}_{2}$, and their performances can be greatly enhanced ${ }^{18}$. However, note that another crucial issue about the visible light utilization still remains in these hetero-nanostructures as a result of their both relatively large band gap $(3.2 \mathrm{eV})^{13}$. In view of efficient solar energy utilization, the design and fabrication of visible-light-responsive $\mathrm{SrTiO}_{3} / \mathrm{TiO}_{2}$ heterostructure nanotube arrays is highly desired because about $43 \%$ of solar energy is visible light while only about $4 \%$ is UV light ${ }^{19}$. Simultaneously, doping transition metals with $\mathrm{SrTiO}_{3}$ material for narrowing its band gap and enhancing absorption of visible light have attracted considerable attention ${ }^{20-22}$. In particular, chromium doping is of great interest because the occupied $\mathrm{Cr} 3 \mathrm{~d}$ level is much lower $(2.2 \mathrm{eV})$ than the conduction band bottom of $\mathrm{SrTiO}_{3}$ determined by the $\mathrm{Ti} 3 \mathrm{~d}$ orbital ${ }^{23,24}$. However, the $\mathrm{Cr}$-doped $\mathrm{SrTiO}_{3} / \mathrm{TiO}_{2}$ heterostructured nanotube arrays for facilitating the charge separation and enhancing the visible light response have rarely been reported up to now.

Herein, we demonstrate a facile synthetic strategy for fabricating uniform Cr-doped $\mathrm{SrTiO}_{3} / \mathrm{TiO}_{2}$ heterostructured nanotube arrays by in situ hydrothermal method using $\mathrm{TiO}_{2}$ nanotube arrays as both template and precursor, and their structure and composition can be rationally tailored by simply adjusting the reaction time. Furthermore, it has been found that the Cr-doped $\mathrm{SrTiO}_{3} / \mathrm{TiO}_{2}$ heterostructure nanotube arrays exhibit much higher photoelectrochemical as well as photocatalytic performances than both pure $\mathrm{TiO}_{2}$ nanotube arrays and $\mathrm{SrTiO}_{3} / \mathrm{TiO}_{2}$ nanotube arrays under visible light irradiation. 


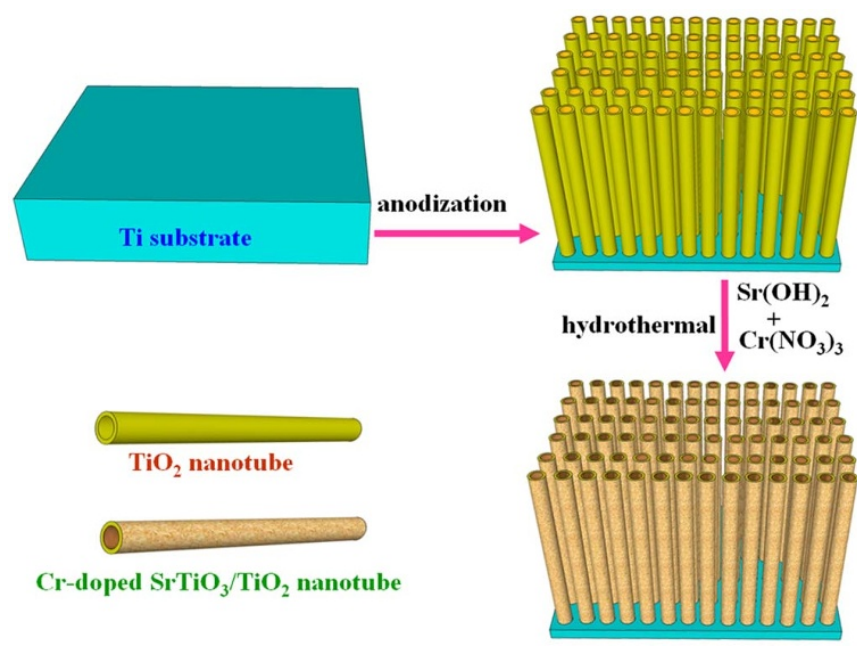

Figure $1 \mid$ Schematic illustration of the synthetic approach of $\mathrm{Cr}$-doped $\mathrm{SrTiO}_{3} / \mathrm{TiO}_{2}$ heterostructure nanotube arrays.

\section{Results}

The fabrication approach of heterostructured $\mathrm{Cr}$-doped $\mathrm{SrTiO}_{3} /$ $\mathrm{TiO}_{2}$ nanotube arrays have been illustrated in Figure 1. Firstly, the well aligned $\mathrm{TiO}_{2}$ nanotube arrays were produced by electrochemical anodization of Ti foil in hydrofluoric medium and then annealed at $500^{\circ} \mathrm{C}$ for $1 \mathrm{~h}$ in air to induce the transformation from amorphous to high crystalline anatase. Secondly, Cr-doped $\mathrm{SrTiO}_{3} / \mathrm{TiO}_{2}$ heterostructure nanotube arrays were synthesized by reacting $\mathrm{TiO}_{2}$ nanotube arrays with $\mathrm{Sr}(\mathrm{OH})_{2}$ in the precence of $\mathrm{Cr}\left(\mathrm{NO}_{3}\right)_{3}$ under hydrothermal treatment, in which $\mathrm{TiO}_{2}$ nanotube arrays were utilized as both template and reactant.

Fig. 2A and Fig. 2B exhibit the typical scanning electron microscopy (SEM) images of the $\mathrm{TiO}_{2}$ nanotube arrays prepared by electrochemical anodization and then anneal while keeping the tubular architectures. It can be observed that $\mathrm{TiO}_{2}$ nanotube arrays consist of uniform nanotubes with an average length of $3.8 \mu \mathrm{m}$, a mean pore diameter of $56 \mathrm{~nm}$, and a wall thickness of about $35 \mathrm{~nm}$ (as shown in Fig. S1). The orifices and the side surfaces of these nanotubes are composed of relatively smooth surfaces without secondary nanostructures. However, when $\mathrm{TiO}_{2}$ nanotube arrays were dipped into an aqueous solution that contains $\operatorname{Sr}(\mathrm{OH})_{2}$ and $\mathrm{Cr}\left(\mathrm{NO}_{3}\right)_{3}$ under hydrothermal treatment, heterostructured $\mathrm{Cr}$-doped $\mathrm{SrTiO}_{3} / \mathrm{TiO}_{2}$ nanotube arrays were obtained. Different from $\mathrm{TiO}_{2}$ nanotube arrays surrounded by smooth surfaces, the side surfaces of $\mathrm{Cr}$-doped $\mathrm{SrTiO}_{3} / \mathrm{TiO}_{2}$ heterostructure nanotube arrays become rough, and the orifices are cracked due to the penetration of $\mathrm{Sr}$ and $\mathrm{Cr}$ cations into $\mathrm{TiO}_{2}$ nanotube arrays (as shown in Fig. 2C and 2D). Furthermore, the amount of Cr-doped $\mathrm{SrTiO}_{3}$ can be rationally tailored by simply adjusting the reaction time (Fig. S2). It can be clearly seen from Fig. S2A that at the hydrothermal reaction time eaual to $0.5 \mathrm{~h}$, the side surfaces of the heterostructured $\mathrm{Cr}$-doped $\mathrm{SrTiO}_{3} /$ $\mathrm{TiO}_{2}$ nanotube arrays are only a little crude. However, further increasing the reaction time up to 1.5 or $2 \mathrm{~h}$, the surfaces of asfabricated $\mathrm{Cr}$-doped $\mathrm{SrTiO}_{3} / \mathrm{TiO}_{2}$ heterostructures gradually become coarser, which can be ascribed to the excessive transformation of $\mathrm{TiO}_{2}$ to $\mathrm{Cr}$-doped $\mathrm{SrTiO}_{3}$.

Additionally, Fig. 2E shows the transimission electron microscopy (TEM) image of the fragments of $\mathrm{Cr}$-doped $\mathrm{SrTiO}_{3} / \mathrm{TiO}_{2}$ nanocomposite obtained through the sonication treatment in the presence of acetone solution. To further determine the specific distribution of $\mathrm{Cr}$, $\mathrm{Sr}$, Ti and $\mathrm{O}$ elements, high angle annular dark field scanning TEM (HAADF-STEM) measurement of the Cr-doped $\mathrm{SrTiO}_{3} / \mathrm{TiO}_{2}$ heterostructure nanotube arrays has been conducted (Fig. 2F). As shown in Fig. 2G-J, it can be clearly seen that the distribution of $\mathrm{Cr}, \mathrm{Sr}$ and Ti elements is homogeneous and uniform, indicating the well dispersal of $\mathrm{Cr}$-doped $\mathrm{SrTiO}_{3}$ on the outer wall of $\mathrm{TiO}_{2}$ nanotubes. Note that the distribution of $\mathrm{O}$ element exhibits a larger area than the other elements, which may be ascribed to the impurity from the copper grid. Besides, the amount distribution of each element has

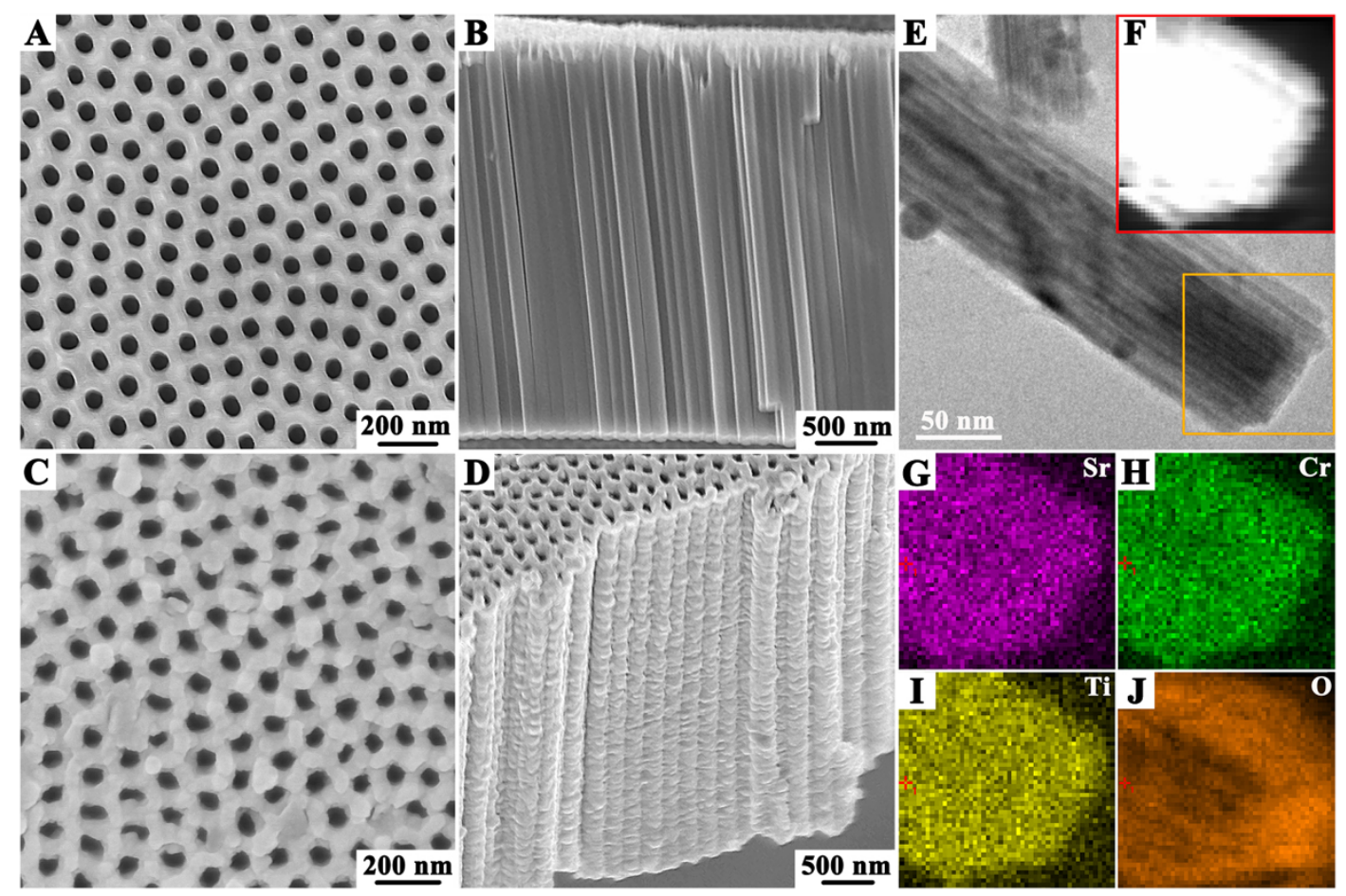

Figure $2 \mid$ SEM images $(\mathrm{A}, \mathrm{B})$ of $\mathrm{TiO}_{2}$ nanotube arrays and $(\mathrm{C}, \mathrm{D})$ heterostructured $\mathrm{Cr}$-doped $\mathrm{SrTiO}_{3} / \mathrm{TiO}_{2}$ nanotube arrays treated with $1 \mathrm{~h}$ hydrothermal reaction times. (E) TEM image, (F) HAADF-STEM image and (G-J) EDX elemental mapping images of the $1 \mathrm{~h}$ treated Cr-doped SrTiO ${ }_{3} /$ $\mathrm{TiO}_{2}$ heterostructure. 
been detected by the energy dispersive X-ray (EDX) spectrum and shown in Fig. S3.

The UV-Vis diffusive absorption spectra of as-prepared $\mathrm{TiO}_{2}$ nanotube arrays and $\mathrm{Cr}$-doped $\mathrm{SrTiO}_{3} / \mathrm{TiO}_{2}$ heterostructures with various growth stages have been shown in Fig. 3A. It can be observed that comparing with $\mathrm{TiO}_{2}$ nanotube arrays, there are evident redshifts in the absorbance peak edges of these heterostructures by increasing the hydrothermal reaction time, which should be due to the amount increase of $\mathrm{Cr}$-doped $\mathrm{SrTiO}_{3}$. Their crystal structure and compostion have been further studied by X-ray diffraction (XRD) and the results have been shown in Fig. 3B, which clearly reveals that the peak intensity of $\mathrm{Cr}$-doped $\mathrm{SrTiO}_{3}$ increases gradually with prolonging the hydrothermal times. Moreover, note that the XRD patterns of the $\mathrm{Cr}$-doped $\mathrm{SrTiO}_{3}$ are nearly identical with the cubic $\mathrm{SrTiO}_{3}$ (Fig. S5), indicating that $\mathrm{Cr}$ cations doping did not introduce any impurities ${ }^{24}$. The comparision of (110) diffraction peaks between $\mathrm{SrTiO}_{3} / \mathrm{TiO}_{2}$ and $\mathrm{Cr}$-doped $\mathrm{SrTiO}_{3} / \mathrm{TiO}_{2}$ heterostructure nanotube arrays (Fig. S6) shows that the peak positon of of $\mathrm{Cr}$-doped $\mathrm{SrTiO}_{3} /$ $\mathrm{TiO}_{2}$ nanocomposites shifts slightly toward a higher degree, implying the partial substitution of $\mathrm{Cr}^{3+}$ cations for $\mathrm{Sr}^{2+}$ in the $\mathrm{Cr}$-doped $\mathrm{SrTiO}_{3} / \mathrm{TiO}_{2}$ heterostructures ${ }^{23}$, which may be due to the smaller ionic radius of $\mathrm{Cr}^{3+}(0.062 \mathrm{~nm})$ than that of $\mathrm{Sr}^{2+}(0.118 \mathrm{~nm})$ but a slightly larger than that of $\mathrm{Ti}^{4+}(0.061 \mathrm{~nm})$. Consequently, it can be concluded that the right or left shift of the peak position generally represents the substitution of $\mathrm{Cr}^{3+}$ cations for $\mathrm{Sr}^{2+}$ or $\mathrm{Ti}^{4+}$, respectively ${ }^{23}$.

Furthermore, X-ray photoelectron spectroscopy (XPS) measurements were carried out to examine the valence states of chromium element in $\mathrm{Cr}$-doped $\mathrm{SrTiO}_{3} / \mathrm{TiO}_{2}$ heterostructure nanotube arrays. As shown in Fig. 3C, the fully scanned spectrum confirms the existence of $\mathrm{Cr}, \mathrm{Ti}, \mathrm{O}, \mathrm{Sr}$ and $\mathrm{C}$ elements. The high-resolution $\mathrm{Cr} 2 \mathrm{p}$ spectrum shown in Fig. 3D reveals that the doublet peaks at 576.9 and $586.5 \mathrm{eV}$ could be indexed to $\mathrm{Cr} 2 \mathrm{p}_{3 / 2}$ and $\mathrm{Cr} 2 \mathrm{p}_{1 / 2}$, respectively. In the $\mathrm{Cr} 2 \mathrm{p}$ spectrum, the sharp peak at $576.9 \mathrm{eV}$ is assigned to the trivalent chromium corresponded to the standard $\mathrm{Cr}_{2} \mathrm{O}_{3}$, and no any other peak e.g. $\mathrm{Cr}^{6+}(580.2 \mathrm{eV})$ is detected, which further demonstrate the substitution of $\mathrm{Cr}^{3+}$ cations with $\mathrm{Sr}^{2+}$ in the $\mathrm{Cr}$-doped $\mathrm{SrTiO}_{3} / \mathrm{TiO}_{2}$ heterostructures ${ }^{23,24}$. In addition, as shown in Fig. S7, the variation of the $\mathrm{Sr} 3 \mathrm{~d}$ peak position is much larger than that of $\mathrm{Ti}$ 2 p, implying that doping $\mathrm{Cr}$ cations into $\mathrm{SrTiO}_{3}$ mainly affects the $\mathrm{Sr}$ sites instead of the Ti sites, which is in good agreement with the above deduced conclusions.

Moreover, the photoconversion efficiencies of as-prepared heterostructured $\mathrm{Cr}$-doped $\mathrm{SrTiO}_{3} / \mathrm{TiO}_{2}$ nanotube arrays have been explored. As shown in Fig. 4A, when all these samples were illuminated with continuous monochromatic light, an intense photocurrent peak at around $370 \mathrm{~nm}$ can be clearly observed (Fig. 4B), the peak edges of the photocurrent response shifted first to right and then to left by increasing of the hydrothermal time. At the reaction time of $1 \mathrm{~h}$, the largest bathochromic shift can be observed and the peak edge of the photocurrent approximated to $500 \mathrm{~nm}$. More specifically, according to the absorption spectra (Fig. 3A), the absorption peak edges red-shifted continuously, the peak edges of the photocurrent should also shift toward right correspondingly. However, the actual measurements did not really confirm this prediction. It is well known that the photoelectrochemical performances are influenced by not only the excitation and separation of electron-hole pairs but also the transport of charge carriers, and the final photocurrent density were determined by the synergistic function of these two factors. Therefore, although the absorption spectra red shifted continuously with the increase of hydrothermal times, the photoconversion efficiency decreased unexpectedly due to the severe destruction of the $\mathrm{TiO}_{2}$ tubular structures (Fig. S2), which go against the electron transport. Moreover, it is generally believed that the recombination of
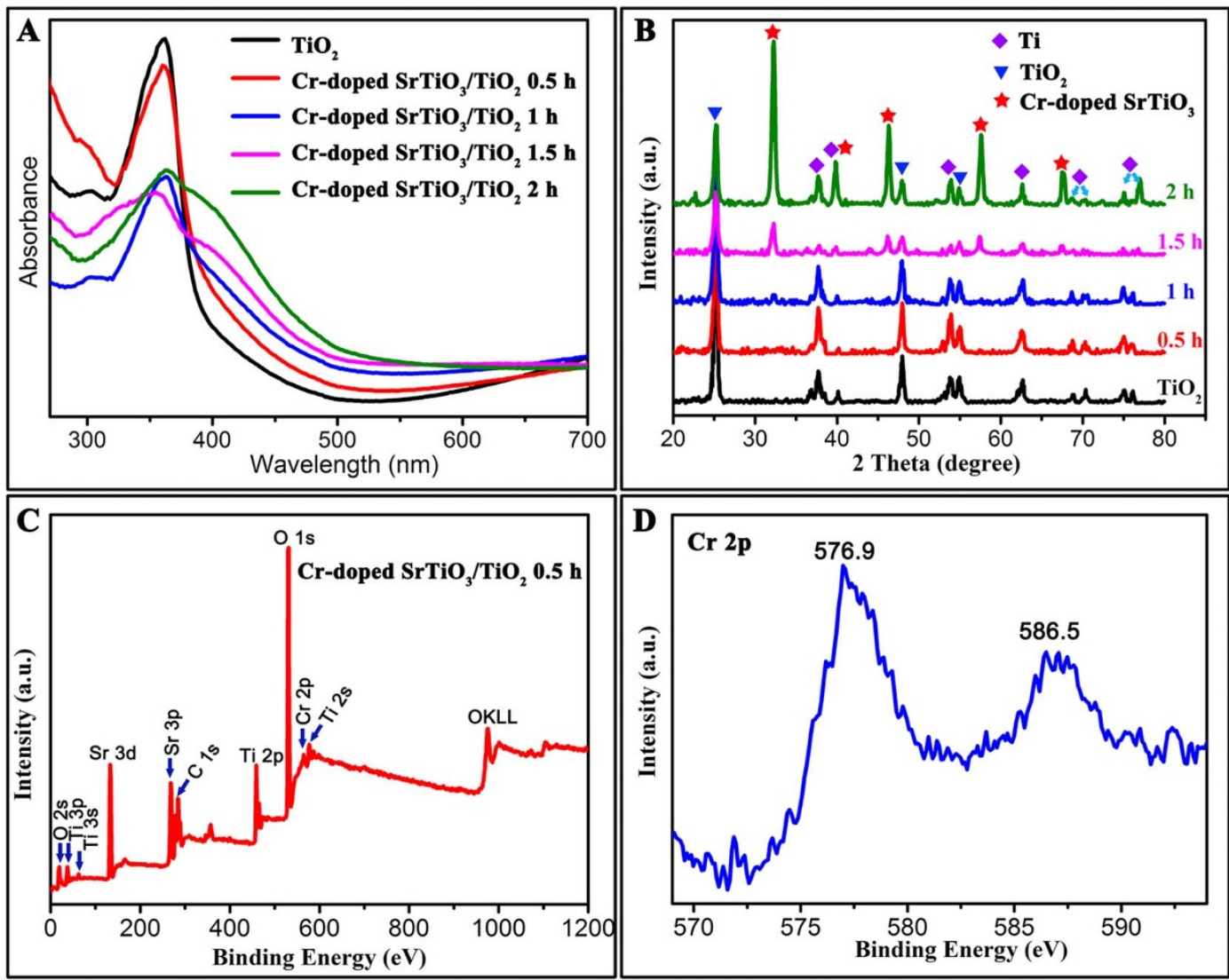

Figure $3 \mid$ (A) UV-Vis diffusive absorption spectra and (B) XRD patterns of $\mathrm{TiO}_{2}$ nanotube arrays and heterostructured $\mathrm{Cr}$-doped $\mathrm{SrTiO}_{3} / \mathrm{TiO}_{2}$ nanotube arrays. (C) XPS spectra and (D) high-resolution Cr 2p XPS spectra of the $0.5 \mathrm{~h}$ treated sample. 

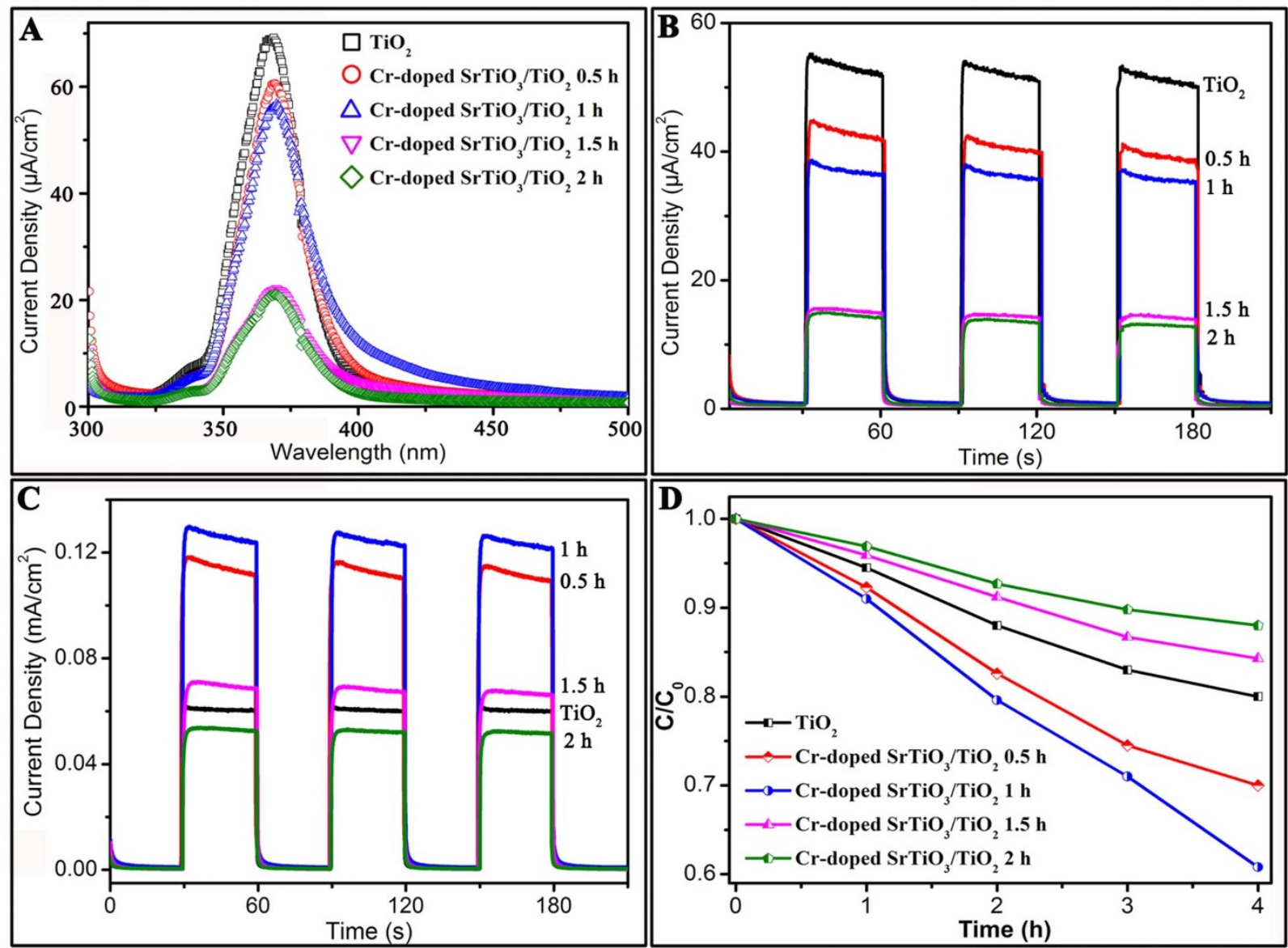

Figure $4 \mid$ Photoelectric conversion performances of $\mathrm{Cr}$-doped $\mathrm{SrTiO}_{3} / \mathrm{TiO}_{2}$ nanotube array under (A) continuous monochromatic light, (B) $372 \mathrm{~nm}$ monochromatic light and $(C)$ visible light irradiation $(\lambda>420 \mathrm{~nm})$ and $(D)$ Photocatalytic performances for RhB degradation under visible light irradiation $(\lambda>420 \mathrm{~nm})$.

photoinduced electron-hole pairs would become more severe at increased doping level because of the formation of more defects, which might be another unfavourable factor for the photoconversion.

As shown in Fig. 4C, when the samples were illuminated under visible light, except for the $2 \mathrm{~h}$ treated sample, all the Cr-doped $\mathrm{SrTiO}_{3} / \mathrm{TiO}_{2}$ nanocomposites exhibited higher photocurrent properties than pure $\mathrm{TiO}_{2}$ nanotube arrays, and the photocurrent of the $1 \mathrm{~h}$ treated sample was twice as high as that of pure $\mathrm{TiO}_{2}$. Moreover, it can be found that the photocurrent of the $\mathrm{Cr}$-doped $\mathrm{SrTiO}_{3} / \mathrm{TiO}_{2}$ heterostructure nanotube arrays increased along with the hydrothermal reaction times before $1 \mathrm{~h}$. With further increasing treatment time over $1 \mathrm{~h}$, the photocurrent density decreased. Hence, it can be deduced that the degree of coverage of $\mathrm{Cr}$-doped $\mathrm{SrTiO}_{3}$ over $\mathrm{TiO}_{2}$ plays a crucial role in determining their photoelectrochemical properties. On the other hand, the photocatalytic behaviours of the asprepared heterostructured $\mathrm{Cr}$-doped $\mathrm{SrTiO}_{3} / \mathrm{TiO}_{2}$ nanotube arrays for the degradation of $\mathrm{RhB}$ under visible light irradiation have also been investigated and shown in Fig. 4D. It can be seen that the photocatalytic activities of these $\mathrm{Cr}$-doped $\mathrm{SrTiO}_{3} / \mathrm{TiO}_{2}$ nanocomposites were in generally accordance with their photoelectrochemical performances except the $1.5 \mathrm{~h}$ treated one, and the $1 \mathrm{~h}$ treated sample still exhibited the highest photocatalytic property.

\section{Discussion}

According to the discussion above, it can be concluded that the $\mathrm{Cr}$ doped $\mathrm{SrTiO}_{3}$ greatly determine the photoelectrochemical and photocatalytic performances of $\mathrm{TiO}_{2}$ nanotube arrays. Figure 5 illustrates the possible mechanism concerning the improved charge separation of $\mathrm{Cr}$-doped $\mathrm{SrTiO}_{3} / \mathrm{TiO}_{2}$ heterostructure nanotube arrays under visible light irradiation. The valence band top of $\mathrm{SrTiO}_{3}$ is lifted up by the occupied $\mathrm{Cr}^{3+}$ level, while the original conduction band bottom determined by Ti $3 \mathrm{~d}$ orbital is hardly affected ${ }^{22}$. Under visible light illumination, the photogenerated electrons of $\mathrm{Cr}$-doped $\mathrm{SrTiO}_{3}$ are photoexcited from the valence band ( $\left.\mathrm{Cr} 3 \mathrm{~d}\right)$ to the conduction band (Ti 3d) and then transferred to the conduction band of $\mathrm{TiO}_{2}$ because the conduction band of $\mathrm{SrTiO}_{3}$ is $200 \mathrm{mV}$ more negative than that of $\mathrm{TiO}_{2}{ }^{13-18}$. As a result, direct coupling of $\mathrm{Cr}$-doped $\mathrm{SrTiO}_{3}$ to $\mathrm{TiO}_{2}$ can not only enhance the visible light response but also reduce the recombination of charge carriers at the surface of the heterostructure. Moreover, the vectorial electron transfer through aligned $\mathrm{TiO}_{2}$ nanotube arrays facilitates charge transport and thus enhances the photoconversion efficiency ${ }^{25}$. Therefore, when $\mathrm{TiO}_{2}$ nanotube arrays were covered by thin and uniform $\mathrm{Cr}$-doped $\mathrm{SrTiO}_{3}$ nuclei through short duration hydrothermal treatment $(\leq$ $1 \mathrm{~h}$ ), the photoconversion efficiency of the heterostructured $\mathrm{Cr}$ doped $\mathrm{SrTiO}_{3} / \mathrm{TiO}_{2}$ nanotube arrays was enhanced greatly. However, further increasing hydrothermal time, $\mathrm{TiO}_{2}$ nanotubes arrays would be coated with high thick and densely packed $\mathrm{Cr}$-doped $\mathrm{SrTiO}_{3}$ nuclei, which could severely destroy the tubular structure and hinder the excellent electron transport ability of $\mathrm{TiO}_{2}$ nanotube arrays. The inner $\mathrm{TiO}_{2}$, being lost in its transformation to Cr-doped $\mathrm{SrTiO}_{3}$, would scarcely make any contribution to the transfer and transport of electrons, and the photocurrent response of the nanocomposites decreased accordingly. The photoelectrochemical performances of hetero-semiconductors are the synergistic results of the excitation of electrons, separation of electron-hole pairs and the transport of charge carriers. In the case of photocatalysis, because the photocatalytic activities are significantly influenced by the separation 


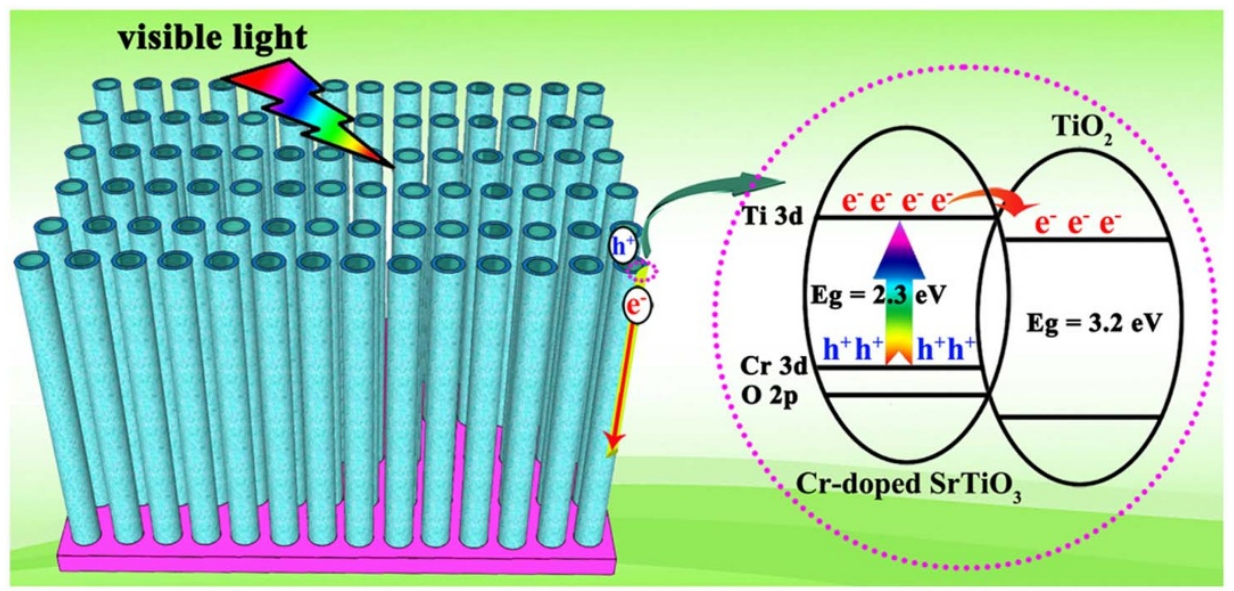

Figure $5 \mid$ Schematic illustration for the charge separation of (A) Cr-doped $\mathrm{SrTiO}_{3} / \mathrm{TiO}_{2}$ heterostructure nanotube arrays.

of electron-hole pairs rather than the transport of charge carriers, the decrease of the photocatalytic performances of these heterostructures may be due to the unfavorable electron transfer and the rapid recombination of electron-hole pairs with the increase of $\mathrm{Cr}$-doped $\mathrm{SrTiO}_{3}$ and the diminish of $\mathrm{TiO}_{2}$.

In summary, we have demonstrated a facile and efficient process for fabricating heterostructured $\mathrm{Cr}$-doped $\mathrm{SrTiO}_{3} / \mathrm{TiO}_{2}$ nanotube arrays. Moreover, their performance studies indicated that the $\mathrm{Cr}$ doped $\mathrm{SrTiO}_{3} / \mathrm{TiO}_{2}$ heterostructure nanotube arrays exhibited higher photoelectrochemical and photocatalytic activities than pure $\mathrm{TiO}_{2}$ nanotube arrays and $\mathrm{SrTiO}_{3} / \mathrm{TiO}_{2}$ heterostructure nanotube arrays without $\mathrm{Cr}$ doping under visible light irradiation. The possible function of chromium element for enhancing their both photoelectrochemical and photocatalytic behaviours has also been discussed detailedly. It is considered that this strategy may also be generally adapted for preparing other metal doped $\mathrm{TiO}_{2}$ based heterostructures, which may have promising applications in both photoelectric conversion and photocatalysis.

\section{Methods}

Chemicals. Titanium foil $(0.1 \mathrm{~mm},>99.9 \%)$ was purchased from Baoji Titanium Industry Co., Ltd. Acetone, ethanol, nitric acid, hydrofluoric acid, ammonium fluoride, chromic nitrate and ethylene glycol were obtained from Sinopharm Chemical Reagent Co., Ltd. Strontium hydroxide octahydrate $\left(\mathrm{Sr}(\mathrm{OH})_{2} \cdot 8 \mathrm{H}_{2} \mathrm{O}\right)$ was purchased from Alfa. Deionized water (18 $\mathrm{M} \Omega$, Molecular) was used for all solution preparations.

Sample preparation. Firstly, titanium foil (purity $>99.9 \%$ ) with $0.1 \mathrm{~mm}$ thickness was cut into strips with $1 \mathrm{~cm}$ width and $3 \mathrm{~cm}$ length. Before anodization, these strips were degreased by sonication in acetone, ethanol and deionized water in turn for about $20 \mathrm{~min}$, and then polished in the mixture of hydrofluoric acid and nitric acid at the ratio of $1: 1$. The titanium strip was placed in a plastic beaker equipped with a platinum slice negative electrode and continuous current power supply. Ammonium fluoride $(0.3 \mathrm{wt} \%)$ and deionized water $(3 \mathrm{wt} \%)$ diluted in ethylene glycol $(200 \mathrm{ml})$ was used as electrolyte. A constant potential of $60 \mathrm{~V}$ was supplied between the two electrodes for $30 \mathrm{~min}$. Subsequently, the strip was washed with ethylene glycol and sonicated for $1 \mathrm{~min}$, and then washed with deionized water and sonicated for $10 \mathrm{~s}$ to remove the surface deposit. At last, these strips were annealed at $500^{\circ} \mathrm{C}$ for $1 \mathrm{~h}$ with a programming rate of $3^{\circ} \mathrm{C} / \mathrm{min}$ for both warming up and cooling down. Well aligned crystalline anatase $\mathrm{TiO}_{2}$ nanotube arrays with the average length of $3.8 \mu \mathrm{m}$ were obtained.

The annealed $\mathrm{TiO}_{2}$ nanotube arrays obtained in the above step were used as both substrate and reactant for the fabrication of $\mathrm{Cr}$-doped $\mathrm{SrTiO}_{3} / \mathrm{TiO}_{2}$ nanocomposites. In general, $5 \mathrm{~mol} \% \mathrm{Cr}$ cations doped $\mathrm{SrTiO}_{3} / \mathrm{TiO}_{2}$ heterostructure nanotube arrays are fabricated as follows. Firstly, $0.25 \mathrm{~g}$ strontium hydroxide $\left(\mathrm{Sr}(\mathrm{OH})_{2} \cdot 8 \mathrm{H}_{2} \mathrm{O}\right)$ and $0.02 \mathrm{~g}$ chromic nitrate $\left(\mathrm{Cr}\left(\mathrm{NO}_{3}\right)_{3} \cdot 9 \mathrm{H}_{2} \mathrm{O}\right)$ was added to $40 \mathrm{ml}$ deionized water with vigorous stirring. Next, the solution was transferred into a Teflon-lined stainless steel autoclave which contains a piece of $\mathrm{TiO}_{2}$ nanotube array strip. The autoclave was kept at $150^{\circ} \mathrm{C}$ in an oven for $0.5,1,1.5$, and $2 \mathrm{~h}$, respectively. After the hydrothermal reaction, the strip was drawn from the autoclave and washed with deionized water, and then dried at $60^{\circ} \mathrm{C}$ for $1 \mathrm{~h}$. Heterostructured $\mathrm{Cr}$-doped $\mathrm{SrTiO}_{3} / \mathrm{TiO}_{2}$ nanotube arrays have been synthesized.
Materials characterization. The morphology and size of the as-prepared products were characterized by using a field-emission scanning electron microscope (JSM$6701 \mathrm{~F}, \mathrm{JEOL}$ ) operated at an accelerating voltage of $5 \mathrm{kV}$. The X-ray diffraction spectra (XRD) measurements were performed on a PANalytical X'Pert PRO instrument using $\mathrm{Cu} \mathrm{K} \alpha$ radiation $(40 \mathrm{kV})$. The XRD patterns were recorded from $20^{\circ}$ to $80^{\circ}$ with a scanning rate of $0.067^{\circ} / \mathrm{s}$. UV-visible diffuse reflectance spectra were taken on a UV-2550 (Shimadzu) spectrometer by using $\mathrm{BaSO}_{4}$ as the reference. The element composition was detected by X-ray photoelectron spectroscope. (XPS, Kratos Axis Ultra DLD). HAADF imaging and STEM-EDX mapping techniques were carried out using an FEI Tecnai TF20 microscope operated at $200 \mathrm{kV}$.

Photoelectrochemical and photocatalytic measurements. The $\mathrm{TiO}_{2}$ nanotube arrays and $\mathrm{Cr}$-doped $\mathrm{SrTiO}_{3} / \mathrm{TiO}_{2}$ nanocomposites were used as photoanodes in the 3-arm photoelectrochemical cell. Photocurrent response under visible light irradiation were recorded with a CHI-660D potentiostat in a sandwich-type configuration using Pt slice as counter electrode, a saturated calomel electrode (SCE) as the reference, and $0.1 \mathrm{M} \mathrm{Na}_{2} \mathrm{SO}_{4}$ solution as electrolyte. A $300 \mathrm{~W}$ xenon arc lamp equipped with an ultraviolet cutoff filter (HSX-F300, Beijing NBeT Technology Co., Ltd) calibrated to $100 \mathrm{~mW} / \mathrm{cm}^{2}$, which was measured with a radiometer (CELNP2000, Beijing Au-light Co., Ltd), served as a light source. The photocurrent response under monochromatic light measurements was performed using a $300 \mathrm{~W}$ Xe lamp and a monochromator (71SWS, Beijing 7-Star Optical Instruments Co., Ltd) at $0.6 \mathrm{~V}$ vs SCE. All experiments were carried out under ambient condition.

In all catalytic activity of experiments, $100 \mathrm{ml}$ rhodamine $\mathrm{B}(\mathrm{RhB})$ solution with an initial concentration of $0.25 \times 10^{-5} \mathrm{~g} / \mathrm{L}$ in the presence of a strip of $\mathrm{Cr}$-doped $\mathrm{SrTiO}_{3} /$ $\mathrm{TiO}_{2}$ nanotube arrays $(1 \mathrm{~cm} \times 3 \mathrm{~cm})$ was filled in a photoreactor, which was then irradiated with a $300 \mathrm{~W}$ Xe arc lamp equipped with an ultraviolet cutoff filter. The degradation of organic dyes was monitored by UV/Vis spectroscopy (UV-2550PC, Shimadzu). At given intervals of illumination, the samples of the reaction solution were taken out and analyzed. Decrease in the concentration of dye solution was measured at $\lambda=554$

1. Roy, P., Berger, S. \& Schmuki, P. $\mathrm{TiO}_{2}$ Nanotubes: synthesis and applications. Angew. Chem. Int. Ed. 50, 2904-2939 (2011).

2. Zhang, Z. \& Wang, P. Optimization of photoelectrochemical water splitting performance on hierarchical $\mathrm{TiO}_{2}$ nanotube arrays. Energy Environ. Sci. 5, 6506-6512 (2012).

3. Ye, M. et al. High-efficiency photoelectrocatalytic hydrogen generation enabled by palladium quantum dots-sensitized $\mathrm{TiO}_{2}$ nanotube arrays. J. Am. Chem. Soc. 134, 15720-15723 (2012).

4. Wu, X., Lu, G. Q. \& Wang, L. Shell-in-shell $\mathrm{TiO}_{2}$ hollow spheres synthesized by one-pot hydrothermal method for dye-sensitized solar cell application. Energy Environ. Sci. 4, 3565-3572 (2011).

5. Varghese, O. K., Paulose, M. \& Grimes, C. A. Long vertically aligned titania nanotubes on transparent conducting oxide for highly efficient solar cells. Nat. Nanotechnol. 4, 592-597 (2009).

6. Liu, S., Yu, J. \& Jaroniec, M. Tunable photocatalytic selectivity of hollow $\mathrm{TiO}_{2}$ microspheres composed of anatase polyhedra with exposed $\{001\}$ facets. J. Am. Chem. Soc. 132, 11914-11916 (2010).

7. Zheng, Z. et al. Facile in situ synthesis of visible-light plasmonic photocatalysts $\mathrm{M} @ \mathrm{TiO} 2(\mathrm{M}=\mathrm{Au}, \mathrm{Pt}, \mathrm{Ag})$ and evaluation of their photocatalytic oxidation of benzene to phenol J. Mater. Chem. 21, 9079-9087 (2011).

8. Tang, J., Cowan, A. J., Durrant, J. R. \& Klug, D. R. Mechanism of $\mathrm{O}_{2}$ production from water splitting: nature of charge carriers in nitrogen doped nanocrystalline $\mathrm{TiO}_{2}$ films and factors limiting $\mathrm{O}_{2}$ production. J. Phys. Chem. C 115, 3143-3150 (2011). 
9. Asahi, R. et al. Visible-light photocatalysis in nitrogen-doped titanium oxides. Science 293, 269-271 (2001).

10. Sun, W. T. et al. CdS quantum dots sensitized $\mathrm{TiO}_{2}$ nanotube-array photoelectrodes. J. Am. Chem. Soc. 130, 1124-1125 (2008).

11. Chen, X., Shen, S., Guo, L. \& Mao, S. S. Semiconductor-based photocatalytic hydrogen generation. Chem. Rev. 110, 6503-6570 (2010).

12. Toledo-Antonio, J. A. et al. Highly quasi-monodisperse Ag nanoparticles on titania nanotubes by impregnative aqueous ion exchange. Langmuir. 25, 10195-10201 (2009).

13. Xin, Y. et al. Bioactive $\mathrm{SrTiO}_{3}$ nanotube arrays: strontium delivery platform on Tibased osteoporotic bone implants. ACS Nano 3, 3228-3234 (2009).

14. Burnside, S., Moser, J. E., Brooks, K. \& Grätzel, M. Nanocrystalline mesoporous strontium titanate as photoelectrode material for photosensitized solar devices: increasing photovoltage through flatband potential engineering. J. Phys. Chem. B 103, 9328-9332 (1999).

15. Hod, I. et al. $\mathrm{SrTiO}_{3}$ recombination-inhibiting barrier layer for type II dyesensitized solar cells. J. Phys. Chem. C 114, 10015-10018 (2010).

16. Zhang, J., Bang, J. H., Tang, C. \& Kamat, P. V. Tailored $\mathrm{TiO}_{2}-\mathrm{SrTiO}_{3}$ heterostructure nanotube arrays for improved photoelectrochemical performance. ACS Nano 4, 387-395 (2010).

17. Zhang, X. et al. Synthesis and photocatalytic activity of highly ordered $\mathrm{TiO}_{2}$ and $\mathrm{SrTiO}_{3} / \mathrm{TiO}_{2}$ nanotube arrays on Ti substrates. J. Am. Ceram. Soc. 93, 2771-2778 (2010).

18. Cao, T. et al. A facile in situ hydrothermal method to $\mathrm{SrTiO}_{3} / \mathrm{TiO}_{2}$ nanofiber heterostructures with high photocatalytic activity. Langmuir 27, 2946-2952 (2011).

19. Chen, X. \& Burda, C. The electronic origin of the visible-light absorption properties of C-, $\mathrm{N}$ - and S-doped $\mathrm{TiO}_{2}$ nanomaterials. J. Am. Chem. Soc. 130, 5018-5019 (2008).

20. Subramanian, V., Roeder, R. K. \& Wolf, E. E. Synthesis and UV-visible-light photoactivity of noble-metal- $\mathrm{SrTiO}_{3}$ composites. Ind. Eng. Chem. Res. 45 2187-2193 (2006)

21. Zou, F. et al. Template-free synthesis of mesoporous $\mathrm{N}$-doped $\mathrm{SrTiO}_{3}$ perovskite with high visible-light-driven photocatalytic activity. Chem. Commun. 48, 8514-8516 (2012).

22. Iwashina, K. \& Kudo, A. Rh-doped $\mathrm{SrTiO}_{3}$ photocatalyst electrode showing cathodic photocurrent for water splitting under visible-light irradiation. J. Am. Chem. Soc. 133, 13272-13275 (2011).
23. Yu, H. et al. Sol-gel hydrothermal synthesis of visible-light-driven Cr-doped $\mathrm{SrTiO}_{3}$ for efficient hydrogen production. J. Mater. Chem. 21, 11347-11351 (2011).

24. Wang, D., Ye, J., Kako, T. \& Kimura, T. Photophysical and photocatalytic properties of $\mathrm{SrTiO}_{3}$ doped with $\mathrm{Cr}$ cations on different sites. J. Phys. Chem. B 110, 15824-15830 (2006).

25. Zhu, K., Neale, N. R., Miedaner, A. \& Frank, A. Enhanced charge-collection efficiencies and light scattering in dye-sensitized solar cells using oriented $\mathrm{TiO}_{2}$ nanotubes arrays. J. Nano Lett. 7, 69-74 (2007).

\section{Acknowledgments}

This work was supported by the "Hundred Talents Program" of the Chinese Academy of Science and National Natural Science Foundation of China $(21273255,21303232)$

\section{Author contributions}

Z.B.J. and Y.P.B. developed initial concept. T.C., X.J.Y. and T.W. designed experiments. Z.B.J. and T.C. performed experiments and analyzed data. Z.B.J. wrote the manuscript. G.X.L., J.H.Y. and Y.P.B. supervised the study. All authors discussed the results and commented on the manuscript.

\section{Additional information}

Supplementary information accompanies this paper at http://www.nature.com/ scientificreports

Competing financial interests: The authors declare no competing financial interests.

How to cite this article: Jiao, Z. et al. Visible-light-driven photoelectrochemical and photocatalytic performances of $\mathrm{Cr}$-doped $\mathrm{SrTiO}_{3} / \mathrm{TiO}_{2}$ heterostructured nanotube arrays. Sci. Rep. 3, 2720; DOI:10.1038/srep02720 (2013).

(c) (i) (2) This work is licensed under a Creative Commons Attributioncc. visit http://creativecommons.org/licenses/by-nc-sa/3.0 